\title{
CONFLICTS OF SOCIAL CLASS IN MOVIES
}

\section{Sopa Marwati,* Nurholis, Hasbi Assiddiqi}

\author{
English Literature, Faculty of Adab and Humanities, UIN Sunan Gunung Djati \\ Bandung, Indonesia \\ e-mail: sofamarwati566@gmail.com
}

\begin{abstract}
Social conflict happens due to diversities of opinion, culture, and ideology in the certain society. It can be discovered in every stratum of society level, social conflict can occur in the upper, middle and lower class. This study explained social class conflicts which were taken from two movies: Parasite (2019) and Joker (2019). This study uses a comparative literary theory by Sussan Bassnet. Th study also used focused on the social class conflict theory by Lewis Coser and the classification of people by Karl Max. The method used in this research is descriptive in technique of analyzing the data was obtaining by categorizing, describing and interpreting the data, then making conclusion. The result showed that in the Parasite and the Joker movies contained of social class conflict, it occurred inter classes of people in a society. based on analysis, it concluded that both of the movie has differences in the social class conflict and the causes of the conflict itself. However, both movies have the same consequences of the conflict. In the Parasite movie social class conflict occurred inter the lower class. While, in the Joker movie, the social class conflict occurred between the upper and lower class.
\end{abstract}

Keywords: comparative literature, conflict, social class, movie

\section{INTRODUCTION}

Conflict is a common cause in life. Every single creature can face various conflicts in its whole life. Conflict makes those who passed it become wiser and better. In (Ginanjar, 2016) the social conflict occurs among many people, such as people versus people, fate, destiny, and even nature. Everyone may have this conflict that the conflict carried into themself. It is called psychological conflict. This study focused on social conflict.

Social conflict happens due to diversities of opinion, culture, and ideology in the certain society. It can be discovered in every stratum of society level, social conflict can occur in the upper, middle and lower class. The statement has association with argument of social conflict by Lewis 
Coser in (Coser, 1957) that social conflict is a struggle over values or claims to status, power, and scarce resources, in which the aims of the conflict groups are not only to gain the desired values, but also to neutralize, injure, or eliminate rivals. Defines conflict as an opposition of interest among various individuals and social groups, which may or may not be overtly observable and may or may not break out into open dispute or physical violence.

The Joker movie is a film by Todd Philips and released on October 4, 2019, in America. While, Parasite movie is a film by Boong Joon-ho and released on May 30, 2019. The Parasite and Joker movie have similarities in social conflict. The parasite is a film that explores social class and the interaction between the upper and the lower class society. Kim Ki-Taek's low-income family tries to improve their family's economy by becoming private tutors to Park's children as a high-class society. Then Ki-Taek has a bad intention that all of his family members cooperate to become workers and get the people who worked with Park before. The conflict seems in the climax when all of the viciousness is revealed. Ki- Taek's father, who initially has the protagonist, suddenly kills Park.

Meanwhile, the Joker movie shows how society treats Arthur's character as a mentally ill figure receiving rejection, betrayal, even being treated like garbage. It makes Artur has character changing as a murderer. In Parasite and Joker movie, there are similarities in the consequences of social conflict. In contrast, the differences between the two films are the social class conflict and the causes of the conflict itself.

\section{LITERATURE REVIEW}

In this situation, literature review can be divided into three parts: analyzing movie as literature, comparative literature and social conflict.

\section{Analyzing movie as literature}

Nowadays, human has increasing technology by making something looks alive. The movie is a series of moving images produced by a camera or animation by visual effects. The movie combines photography, sound recordings, fine arts, theater, literature, architecture, and music art. The movie is cinema or moving images, is a series of pictures projected on a screen aims to create the illusion (description) of motion of the living (Weston, 2003).

Through action, pictures, and words, and through recreating human existence, films exalt the human intellect (Ramrao, 2016). The movie can be concluded as a social communication medium with two senses, sight, and hearing, showing social reality where the movie itself grows. It happened 
because the movie can reach all generations around the world. They enjoy wherever the movie comes from by using dubbing voice with translated their language.

\section{Comparative literature}

Comparative literature is a study of two literary works or groups of literary works and the other field. Comparing literature is not only about similarities and differences but also beyond literary works. Basnet in (Bassnet, 1933) stated that comparative literature involves studying texts across cultures, multidisciplinary, and is concerned with the pattern of connection found in literature throughout time and place. Occasionally, a reader may be driven to investigate parallels between works or writers from disparate cultural contexts. Comparative literature makes the exploration larger and a lot of value because it focuses not only on literary works but also on aspects in the literary work.

According to Endraswara (Rusdianti, 2018), he explained the combination of American and scholarly and France Scholarly of Comparative Literature. First, Comparative literature's object of research can be some literary works that are coming from a different country. Second, Comparative literature's object of research can be some literary works from different regions from the same country. Third, Comparative literature can focus on the genre, value, and other elements of literary works. And the last, Comparative literature can compare literary works with other subjects of study such as art, religion, philosophy, music, and any other subject study.

\section{Social Conflict}

Conflict can occur because of different sights or thoughts. The conflict happened among two or more characters. It can be individuals and fate, destiny, or nature, even individuals and themselves, namely psychological conflict. Karz in (Ginanjar, 2016) argues that conflict is antecedent conditions or someone's struggle. It is the appreciation of human activity. A normal human conflict occurs in an all-important relationship. Sujono in (Utami, 2017) states that a conflict is a challenge of one person with another, groups of people, or forces that seem to be moving to words resolution, gaining interest and complication until the turning point.

De Genova said (DeGenova, 2008) that conflict is a natural part of life. It happens in every relationship since two individuals never always agree on a course of action. However, conflict is a fundamental problem in life as a human being. Sayuti (Sayuti, 2000) divided the conflict into three. The first is psychological conflict, and This conflict is about struggling to fight their 
selves. The second is a conflict between two or more; individuals versus society, namely social conflict. This kind of conflict can occur in social life. The third is the physical or element conflict. This conflict happened between man and nature.

The three kinds of conflict above can be concluded into two. According to Stanton in (Arifuddin, 2014) conflict is classified into external and internal. External conflict occurs between a character and something outside. External conflict occurs between two individuals, two groups of individuals, one individual and his environment, and even with nature (social conflict). By contrast, they experience internal conflict with themselves (psychological conflict).

\section{METHOD}

This study uses a comparative literary theory by Sussan Bassnet. The researcher also used focused on the social class conflict theory by Lewis Coser and the classification of people by Karl Max. The method used in this research is descriptive in technique of analyzing the data was obtaining by categorizing, describing and interpreting the data, then making conclusion. This study applied descriptive qualitative approach which is research with qualitative method is research relied on verbal and non numerical data as the basic of analysis and solving the problem appears. A qualitative approach is used because the researcher wants to analyze something is in the two films being compared.

\section{FINDINGS AND DISCUSSIONS}

\section{Social Class Conflict in Parasite Movie}

Conflict can make the movie seem like real life because Life in society can be separated from a conflict. The term "conflict" comes from the Latin "conflicts," which means conflicting or disharmony when individuals or groups of people are trying to get the goals in their own life. Conflict is a situation in which there are two opposing ideas, opinions, feelings, or wishes. Meanwhile, Dean and Mary Tjosvold (1995:184) stated that conflict identifies issues, creates incentives to explore problems, and provides media to move toward resolution. It is through conflict that agreement, unity, and justice can be reached. Based on the definitions above, it can be concluded that conflict is a clash or fight between two or more people or groups for power, property, etc. The conflict occurs because of various causes, such as different arguments or disagreements of ideas and feelings. 
In the Parasite movie, conflict occurred between two lower classes family, the Kim family and the Mun-Kwang family. Mun-Kwang was in Park's house for a long time ago, and she worked for Park's family as a household. As told in the synopsis, the Kim family fakes their identity to chase away all of the people who work for Park. Ki-woo faked his identity as Kevin, pretending to be an educated teacher for tutoring Da-Hae, Park's daughter. Next, Ki-Jung, sister of Ki-woo, is pretending to be an art teacher for Da-song. After that, Ki-Jung got the driver fired and replaced by his father.

Almost perfect, Park and his two children have succeeded in replacing all the employees. But there is one person that must be expelled from this house that is the household Mun-Kwang. The plan begins when Da-Hae, Park's daughter, said that she couldn't get the peach fruit because her household has an allergy.

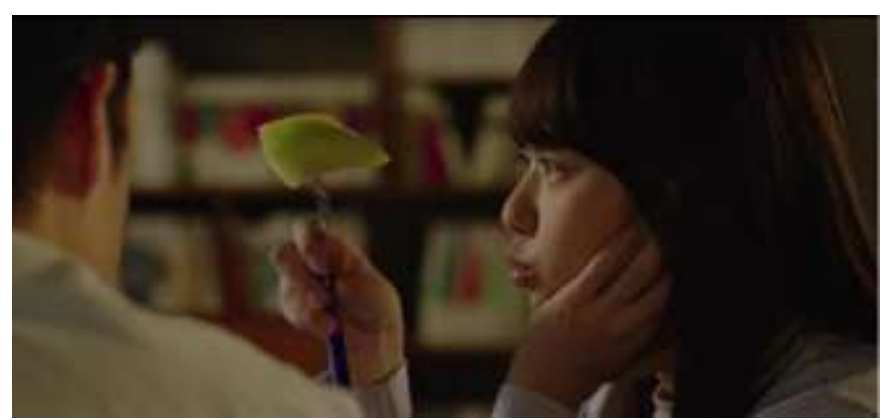

00:40:08

Da-Hae is griping about the fruit plate Mun-Kwang brought. She picks up an apple slice and lovingly feeds it to Ki-Woo.

Da- $\quad$ : I'm so sick of apples. I want peaches.

Hae : Then why don't you just ask for them?

Ki-woo : We can't have peaches. It's forbidden fruit in our house. The

Da-hae housekeeper has a severe peach allergy. If she even goes near a peach, she'll turn red and start hyperventilating. Full-on asthma attack. Does everything but kill her. 
According to Robbins (1979, p. 290) that conflict has four stages: potential opposition, cognition and personalization, behavior, and outcome. In the process of conflict, there is potential opposition that is the first step in the conflict. This step presents a condition that creates opportunities for conflict to arise. Ki-woo used this chance to get Mun-Kwang, the household, out from Park's house. He got the peach, then used a sharp razor to shave off the fuzz around the peach and poured it into a transparent pen cap. The next day afternoon, he walked out of the Park's house after another lesson. He poured the peach fuzz fruit to Mun-Kwang's back, who is in the yard handing out feeds the dog. Ki-Woo took out his pen as he passes Mun-Kwang. He opened the cap and gently poured peach fuzz over her back.

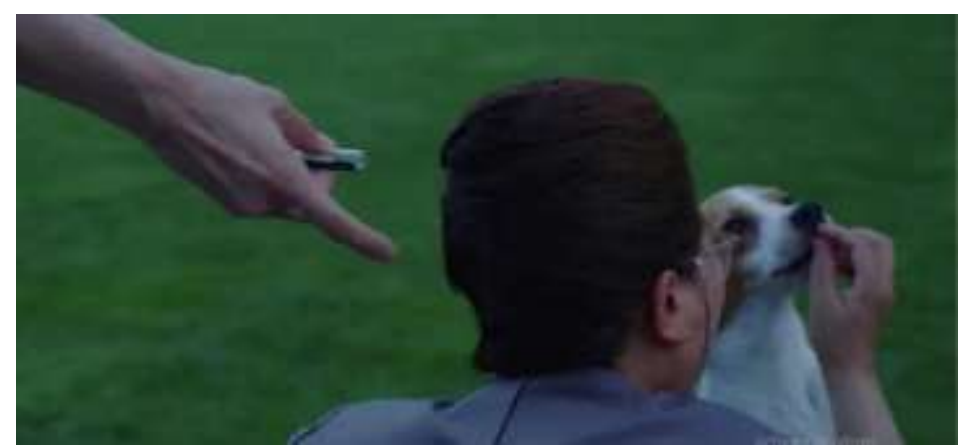

$00: 40: 42$

Ki-woo walked out and heard coughing from inside. It was Mun-Kwang. Then, Mun-Kwang decided to check her condition at a hospital, and she was unaware that Kim watched her from several feet away. He took out his phone and took a selfie, making sure to include Mun-Kwang in the background. Then, Kim showed the picture to Mark's wife and said that Mun-Kwang has a chronic disease. They just arrived home and heard the coughing of Mun-Kwang.

Mun-Kwang, coughing like a sick dog she came out to greet her and Kim. MunKwang tried to take the bags from Kim, but the coughing becomes unbearable, and she ran to the kitchen. She tried to stifle her cough with a napkin and threw the napkin in the trash, and rushes to the bathroom. Directly, Kim reached the trash and put the red sauce on the napkin, and showed that to Park's wife. 


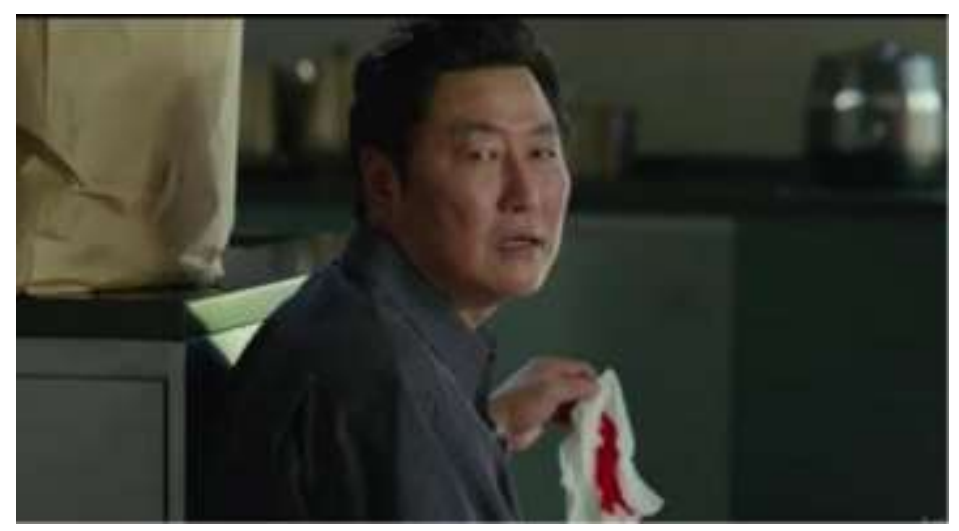

00:44:20

Kim's plan succeeded in making Mun-Kwang fired out from Park's house. His wife, Chung-sook, replaced Mun-Kwang as a household. As stated in chapter two, conflict can occur because several reasons. One of them is getting what they want or need. Kim's family uses many ways to make what they want to be realized.

The conflict started at the turning point of the movie. In this scene, the Parks leave their house for a camping trip. The Kims gathered in Park's house to enjoy the food and the facilities. Suddenly, Mun-Kwang asked to enter the house to meet her husband, who lives in a semi-basement located underground of the house. Nobody knows that place because who has designed this house didn't expose the place to the Park family.

$\begin{array}{ll}\text { Chung-sook } & \text { : Some balls you got. Well, now I know too! And I know } \\ \text { what I'm going to do! Chung-Sook takes out her phone. } & \text { Call the fucking cops. } \\ \text { Mun-Kwang drops to her knees and starts begging. } & \\ \text { Mun-Kwang } & \begin{array}{l}\text { : No! Please, sis! (sobs) We're all in the same boat, } \\ \text { aren't we? We all need a little help to get by. } \\ \text { Chung-sook }\end{array} \\ \text { Mun-Kwang } & \begin{array}{l}\text { anybody's hot your fucking sister, bitch. And I don't need } \\ \text { : Well, I do! I don't have a house. I don't have money. }\end{array}\end{array}$


The conversation above described that conflict occurred between two classes of poor people in the same situation to make his life better. It is that Chung-sook gave pressure to Mun-Kwang, which could make her leave Park's house. Mun-Kwang was trying to ask for help and told the truth that her husband has a debt, and outside is not safe for him. But it didn't work. Unfortunately, the Kims who are listening to the conversation fell from the stairs. Mun-Kwang confused. It's Kevin, Jesica, and Mr. Kim. Kim's family's face and voice are clearly recorded on video. The video is already being prepared to be sent on Mun-Kwang's messenger application. This conflict is kept running between these two groups. As seen in the images and conversation below :
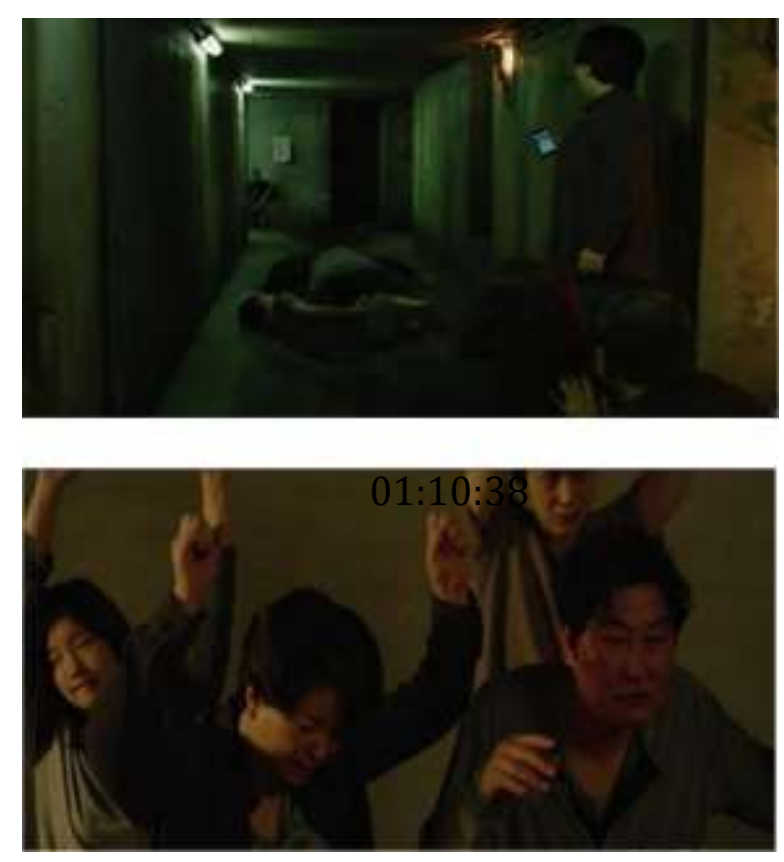

01:13:17

Picture 22 and 23

Mun-kwang

Ki-woo

Mun-kwang

Chung-sook

Mun-kwang

Mun-kwang
: Now I get it. You're all a family. A family that scams people together.

: It's not like that-

: I knew something was off when Yun was fired for no reason. You despicable-

: Listen, sis-

: I'm not your sister, you life-ruining bitch.

Mun-Kwang shows Chung-Sook her phone.

: Why don't I send this little video to Mrs. Park right now? 


\section{Social class conflict in Joker movie}

The social class conflict started in The Joker movie when Arthur's mother, Penny, asked about Thomas Wayne's response to her letters. She said that Wayne would help them for a better life because she has worked for that family for years. But, when Penny wrote the letter for the umpteenth time, Arthur read the letter, and it shocked him.

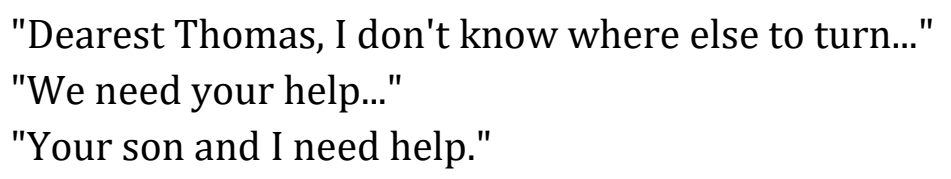

Penny wrote a letter to Thomas Wayne that Arthur was his son. After knowing that, Arthur came to Wayne's home. Arthur walked down a small hill alongside an intimidating brick wall, surrounding the estate like a prison. From this angle, he can peer over the wall, catching a glimpse of an innocent-looking little boy tracking him from behind the trees, hiding as he follows.

Arthur was trying to make the little boy smile and do magic, but it failed. Then, he reached both hands through the gate and firmly took the little boy's face in his hands and used his thumbs to hook the corners of the boy's mouth and pulls them up into a smile, into a "comedy mask." Someone just came and got mad at Arthur. Arthur explained himself as Wayne's son, and Penny Fleck was his mother. He told Arthur to go away from the get and would call the police. The conflict shows in the scene below:
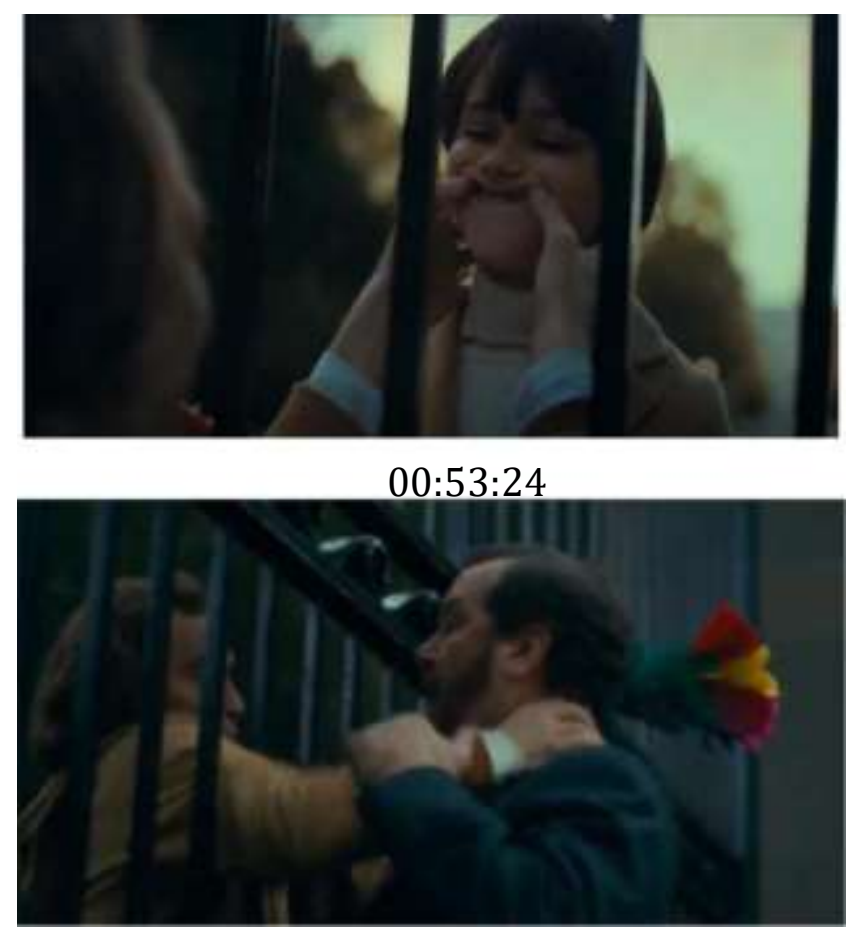

$00: 54: 50$

Arthur : No, please. my mother's name is Penny Fleck. She used to work here, years ago. Can you tell Mr. Wayne that I need to 
see him?

Alfred : you're her son? Arthur, did you know her?

Arthur : I know about the two of them. My mother told me everything.

Alfred : There's nothing to know. There is no "them." your mother was, was delusional. She was a sick woman.

Arthur $\quad$ : No. No, just let me speak to Mr. Wayne.

Not stopping there, Arthur immediately approached Wayne in a luxury building guarded by several police officers because residents were holding a rally against Wayne. He slipped without anyone noticing he was in.

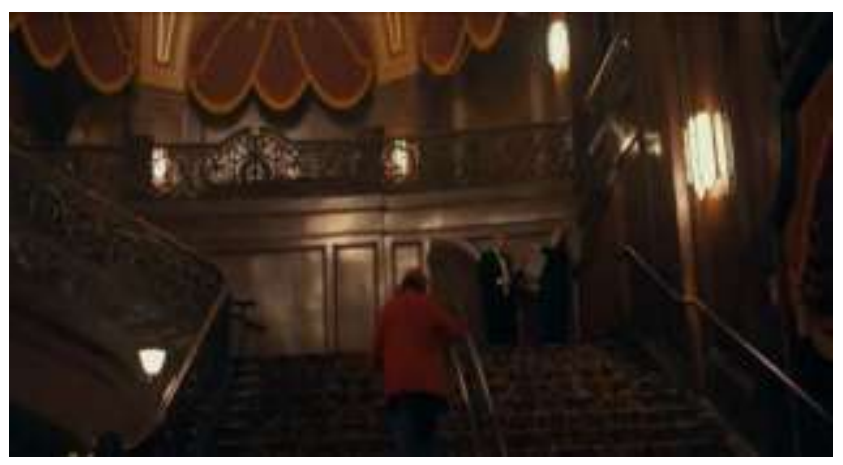

01:03:23

Wayne : Look, pal, I'm not your father. What's wrong with you?

Arthur : How do you know?

Wayne : Cause you were adopted. And I never slept with your mother. What do you want from me, money?

Arthur : No. What? I wasn't adopted.

Wayne : She never told you? Your mother adopted you after she worked for us. She was arrested when you were four years old and committed to Arkham State Hospital. She's batshit crazy. 
Arthur stressed out. He came to the Arkham State Hospital, where his mother, Penny, was interviewed for her psychiatric assessment over 30 years ago. And found the document that he was an adopted child. Arthur did not believe it. His mom has lied to him. Arthur went to the hospital and met his mother. He let go of her hand, getting up fast from the chair like a vampire.

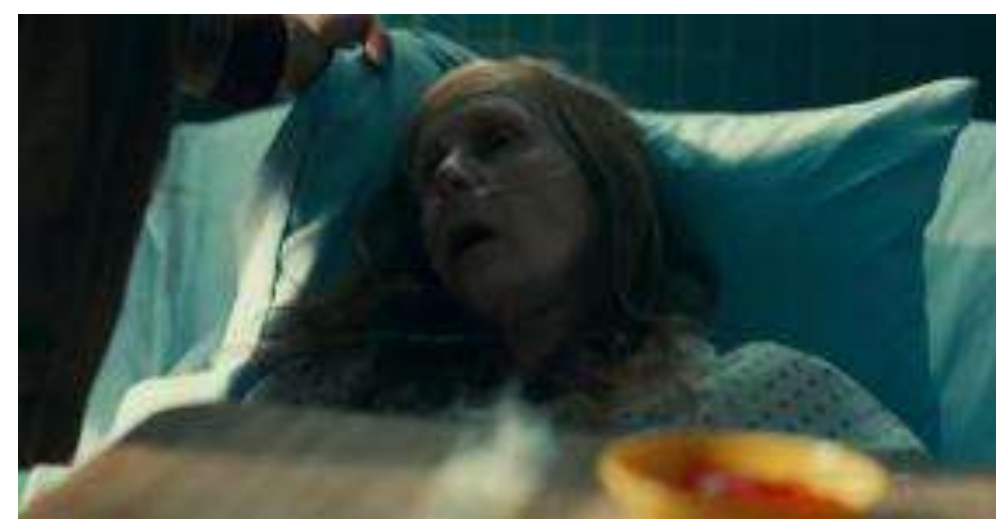

$01: 21: 12$

Arthur :But you know what's funny? Do you know what really makes me laugh? I used to think my life was nothing but a tragedy, but now, now I realize it's all just a fucking comedy.

He reached behind her, grabs one of her pillows as he leaned down closer, face-to-face with her, smiling wide. He covered his mother's face tightly till she died.

\section{The consequences of the conflict in Parasite and Joker movie}

Social conflict may have positive and negative consequences. As stated in chapter two:

The effects of conflicts will be making several effects such as enhance solidarity among group members (in-groups) which conflicted with other groups, the rift between the wars faction, Personality changes in individuals, such as the emergence of a sense of revenge, hatred, and distrust, Property damage and even loss of human lives.

Domination conquest event one of the parties involved in the conflict. The pictures below are the positive and negative consequences of the conflict: 


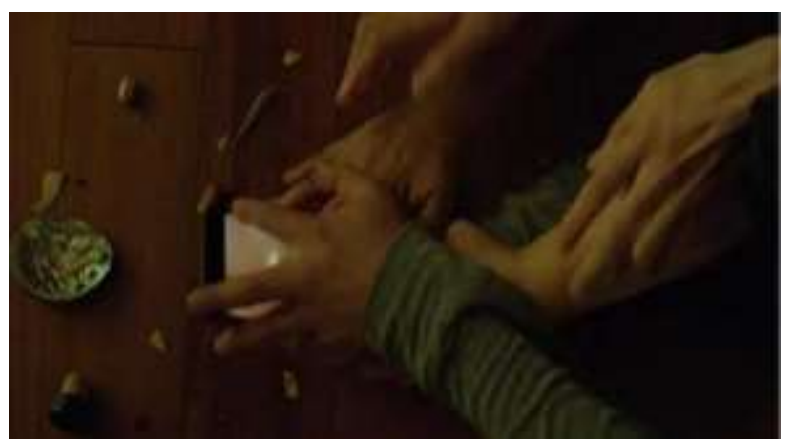

$01: 14: 51$

The picture shows the Kims and Mun-Kwang snatched phone to delete the video. It tells that one group of this conflict has solidarity with each other. Solidarity of the group will arise when the conflict involves different parties, which triggers a conflict between the conflicting parties. Because of conflict, the group concerned will cooperate with other parties who are willing to help them.

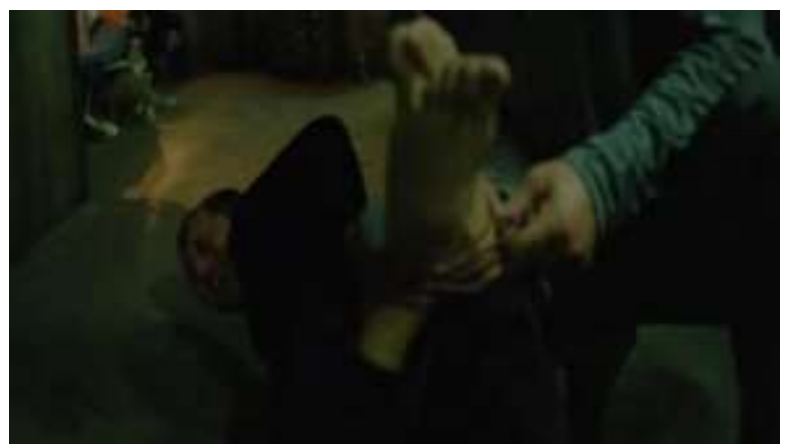

01:17:23

Meanwhile, the picture above shows that the negative consequence of the conflict is violence against Mun-Kwang's husband. Whereas, Ki-woo has tied his feet. The conflict made violence even war occurred, and it will impact that loss of material and even human lives.

At the end of the story, Mun-Kwang's husband, Kun-sae, who lived in an isolated place, ran into individual personality change. He came out from the semi-basement and got closed with the garden party to kill the Kim's. Before, Kun-Sae picked up the viewing stone and raised it to deliver the final blow. He swung it mightily at Ki-Woo's head. It happened because he felt threatened by the Kim family, who has attacked him. This is also the consequence of the conflict. People who have uncommunicative personalities, patients, and powerless can become aggressive even become a murderer. It can be seen below: 


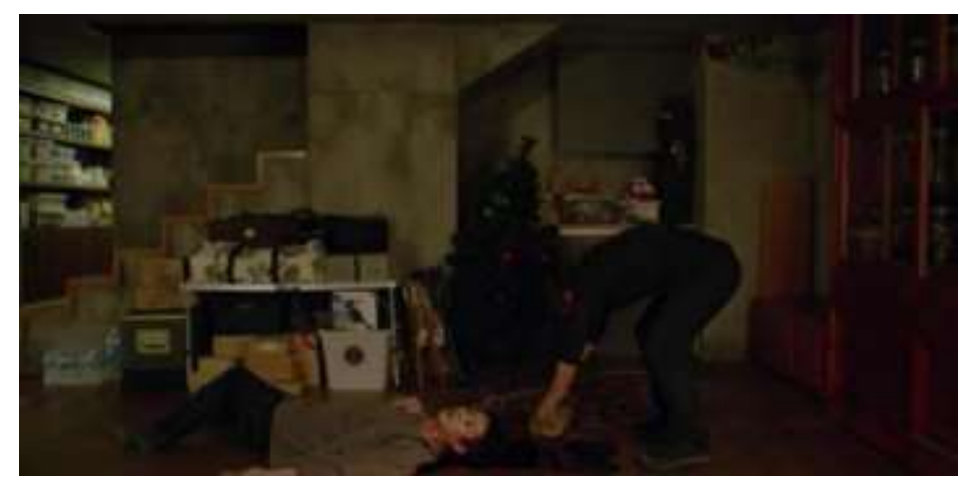

01:52:09

If conflict causes violence, then it will affect in loss of property even lives. This happens in the Parasite movie. After slamming stone to Kiwoo's head, Kun-Sae picked up a large kitchen knife from the sink and walked toward the garden party. Everyone screamed, and Kun-sae killed Jessica with the knife. The knife plunged into Jessica's chest. This made Chungs-sook angry, and she turned the grill over, spilling charred meat and firewood over Kun-Sae. As can be seen below, the scene shows that conflict has several consequences that made many effects. The conflict between Kim and Mun-Kwang families affected damaging properties and even losing lives.

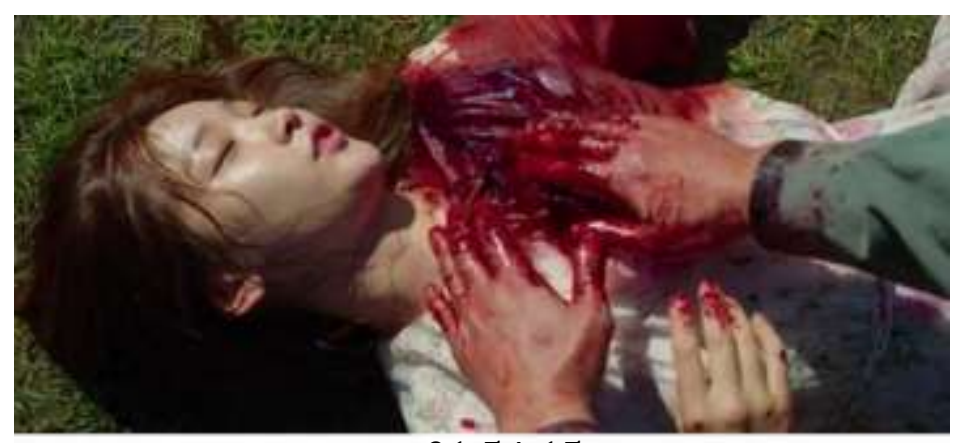

\section{$01: 54: 15$}

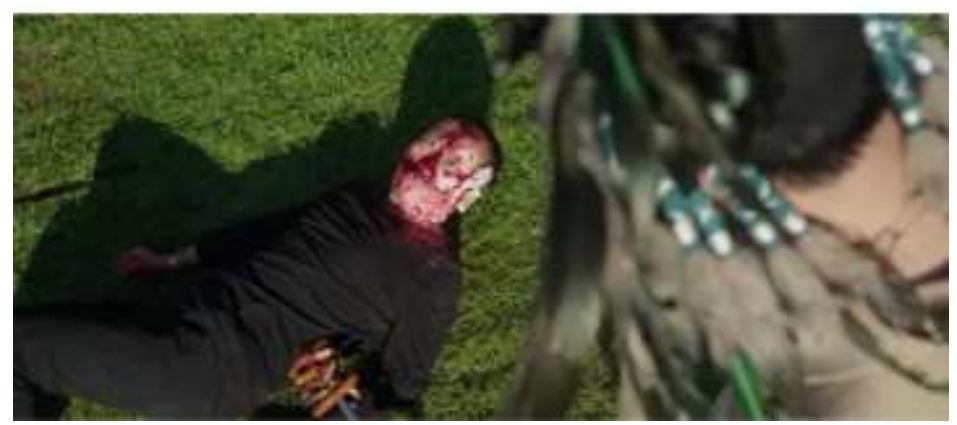

01:54:49

In Lewis Coeser's theory, he focused on the function of conflict. According to him, the conflict has a variety of functions, that conflict can 
strengthen the group's solidarity. Lewis Coser divided some conflict functions such as build group solidarity, alliances with other groups, Character change and communication media

According to Mulyati (2019), any conflict certainly has its consequences. The consequences are a condition caused by certain causes. In every conflict, there will be consequences. The consequences of the conflict are divided into five points as follows: Stronger sense of group solidarity, destruction of group unity, changes in individual personality destruction of existing social values and norms, loss of property and fall of human sacrifice.

Conflict also changed one's identity. Arthur, who was initially gentle, confident, finally experienced individual change. Arthur's profession as a clown has a loving instinct that he shows in the early scenes. He comforted the little boy on the bus. Secondly, she loves her mother very much. She takes good care of her mother. The character changes after experiencing some conflicts. He became brutal even became a murderer.

\section{CONCLUSIONS}

Conflict is a condition of two people or groups that against each other's goals. According to Lewis Coser states that Social conflict is the struggle between opponents over values and claims to scarce status, power, and resources. Social conflict occurs in society, it happens between two or more people fight each other in social interactions (Walker, 2005). Whereas, Karl Max saw the conflict as a classic conflict between rich and poor. The causes of rich and poor conflict is an economic issue that gives power to one another (in weber: 2010).

Based on the result of the research can be concluded that this study found the social class conflict and its consequences. In the Parasite movie social class conflict occurred inter the lower class. The Kim Ki-taek family, the lower class family hopes that they have a better life by working for Park family, the upper class. Like Mun-Kwang, she also imagined always having a comfortable life with her secret that hid her wife in the basement. The statement above shows that the social class conflict happened because of the economic factor. Because of the conflict is not resolved correctly, then one of them was killed. 
While, in the Joker movie, the social class conflict occurred between the upper and lower class. It began when Arthur, as the lower class people went home by subway, saw three drunk men harassing women. Moreover, Arthur has a condition where he can't control his laughed that called mental illness. He laughed louder and louder. Suddenly he was attacked by those people and the conflict ran between Arthur and the three people. Then, the murder occurred.

The researcher saw the differences and the similarities, the differences of the Parasite and the Joker movie can be seen in the social class conflict, the social class conflict in the parasite movie occurred inter the lower class people. While, in the Joker movie, the social class conflict occurred between the lower and the upper class people. The differences can also be seen in the causes of the conflict and its economic and mental illness factors. Whereas, the similarities between them are the consequences. As explained in chapter two, that conflict has positive and negative effects. It shows in Parasite and Joker movie, after the conflict they have stronger solidarity in their group as the positive consequence. While the negative one in the two movies has the same conflict consequences, it is murder.

\section{REFERENCES}

Arifuddin. (2014). AN ANALYSIS OF SOCIAL CONFLICT IN RICK RIORDAN'S NOVEL "THE RED PYRAMID." Adab and Humanities Faculty of UIN Alauddin Makassar.

Bassnet, S. (1933). Comparative Literature. Cambridge. Blackwell.

Coser, A. L. (1957). Social Conflict and The Theory of Social Change. British Journal of Sociology.

DeGenova, M. K. (2008). Intimate Relationship, Marriages, and Families (7th ed.). McGraw-Hill.

Ginanjar, A. (2016). Social conflict of the main character in Charles Dickens' Great Expectations. Universitas Negeri Sunan Gunung Djati Bandung.

Ramrao, T. N. (2016). Film and literature: An overview. Epitome Journals: International Journal of Multidisciplinary Research.

Rusdianti, A. (2018). Comparative Study: Characters and Characterization in 'Twilight' Movie, 'Twilight' Movie Script, 'Descendants of the Sun' Drama, and 'Descendants of the Sun' English Translated Drama Script. State Islamic University Sunan Gunung Djati Bandung.

Sayuti, S. A. (2000). Berkenalan dengan Prosa Fiksi. Gama Media. 
Utami, N. (2017). AN ANALYSIS OF STATE CONFLICT THE MOVIE “ BLACK HAWK DOWN ."

Weston, J. (2003). The Film Director's Intuition: Script Analysis and Rehearsal

Techniques. USA: Michael Wiese Productions. 